\section{Formation constant}

The formation constants were calculated both graphically and by calculations. The average number of ligand molecules bound per metal ion is given by the expression

$$
\bar{\eta}=\frac{C_{\mathrm{A}}-\left(\mathrm{H}^{\oplus} / K+1\right) A^{\ominus}}{C_{\mathrm{M}}} .
$$

Where $A^{\ominus}$ is the free ligand concentration and is given by the expression.

$$
A^{\ominus}=\frac{(1-a) C_{\mathrm{A}}-\mathrm{H}^{\oplus}+\mathrm{OH}^{\ominus}}{\mathrm{H}^{\oplus / K}} .
$$

The formation curve was obtained by plotting $\bar{\eta}$ against $-\log A^{\odot}$, The $-\log A^{\ominus}$ value at $\bar{\eta}=0.5$ gives the value of $\log K$. The values are given in the Table II.

Further the values of the stability constants were calculated by the formula

$$
K=\frac{C_{\mathrm{A}}-\beta\left(A^{\ominus}\right)}{A^{\ominus}\left[C_{\mathrm{M}}+\beta A^{\ominus}-C_{\mathrm{A}}\right]} .
$$

where

$$
\beta=\frac{\left(\mathrm{H}^{\oplus}\right)}{K}+1 \text {. }
$$

The free energy of the complex formation at $25^{\circ} \mathrm{C}$ has been calculated by the formula

$$
-\Delta F=R T \ln k \text {. }
$$

\section{Results and Discussion}

The dissociation of the reagent can be represented as<smiles>[R][Y9]1([R])CC(=O)C1C(=O)C1C(=O)C2=C(CCCC2)C1=O</smiles><smiles>[R][Y19]([R])=CCC(=O)C1C(=O)C2=C(CCCC2)C1O</smiles><smiles>[R][Y8]([H])([H])CC(=O)C1C(=O)C2CCCC1C2CC</smiles>

The probable structure of the metal-complex may be represented as

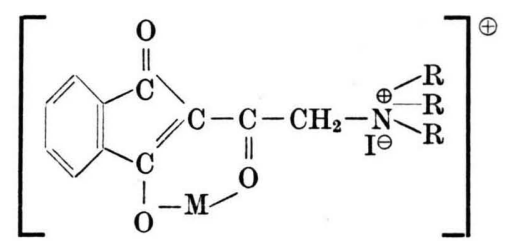

where $\mathrm{R}=\mathrm{CH}_{3}, \mathrm{C}_{2} \mathrm{H}_{5} ; \mathrm{M}=\mathrm{Cu}(\mathrm{II}), \mathrm{Fe}(\mathrm{II})$.

The authors' sincere thanks are due to the Director, Defence Laboratory, Jodhpur, and Prof. R. C. KAPOOR, Head of Chemistry Department University of Jodhpur for providing necessary facilities.

\title{
Formation Constants of some Bivalent Metal Ion Chelates of N(2-hydroxy-1-naphthalidene) Anthranilic Acid (Schiff Base)
}

\author{
R. K. Mehta, V. C. Singhi, and R. K. Gupta \\ Department of Chemistry, University of Jodhpur, Jodhpur (India)
}

(Z. Naturforsch. 26 b, $867-869$ [1971] ; received May 25, 1971)

\begin{abstract}
Protonation constants ( $\log K_{1} \mathrm{H}$ and $\log K_{2}{ }^{\mathrm{H}}$ ) of the $\mathrm{S} \mathrm{ch}$ iff base derived from 2-hydroxy-1naphthaldehyde and anthranilic acid and, the formation constants of certain bivalent metal ion chelates have been determined potentiometrically in 50 per cent (vol./vol.) dioxan solutions $(\mu=$ $0.1 \mathrm{M} \mathrm{NaClO}$ ). The stabilities of these metal chelates are in the order, $\mathrm{UO}_{2}>\mathrm{Cu}>\mathrm{Ni}>\mathrm{Co}>$ $\mathrm{Zn}>\mathrm{Cd}$, in which the sequence of those of first transitional metal ion chelates are in agreement with Irving and Williams order.
\end{abstract}

No systematic study of the formation constants of bivalent metal ion chelates of $N$-(2-hydroxy-1-naphthalidene) anthranilic acid (abbr. $\mathrm{H}_{2} \mathrm{NA}$ ) has been carried out. It is, therefore, of interest to investigate the protonation constants of $\mathrm{H}_{2} \mathrm{NA}$ and formation constants of its metal chelates. The measurements were carried out in 50 per cent dioxan at $30 \pm 0.1^{\circ} \mathrm{C}$ as the ligand and its metal chelates are insoluble in water. 


\section{Experimental}

\section{Apparatus and reagents}

Precision pH-meter Type: OP-205 No. 837 made in Hungary, with glass-calomel electrode assembly was used to determine the change in hydrogen ion concentration of the solution due to complexation. An inert atmosphere of nitrogen was maintained by bubbling oxygen free nitrogen gas through the solution. The electrode system was calibrated at two $\mathrm{pH}$ values; at $\mathrm{pH} 4.0$ with potassium hydrogen phthalate and at pH 7.0 with potassium hydrogen phosphate and sodium hydroxide buffers. Metal ion solution were prepared from their nitrates (BDH-AnalaR) and standardised by the usual methods ${ }^{1}$. Chemically pure sodium perchlorate was used to keep the ionic strength constant. Standard carbonate-free sodium hydroxide was prepared and its solution in 50 per cent dioxan was used as a titrant ${ }^{2}$. Dioxan was refluxed with sodium for 24 hours and distilled before use. The $\mathrm{H}_{2} \mathrm{NA}$ was prepared, purified by repeated crystallisation from ethanol; m.p. $239^{\circ} \mathrm{C}$, and its solution was standardised potentiometrically. All the chemicals used were of reagent grade quality.

\section{pH-titration procedure}

The determination of formation constants was carried out using CALVIN-BJERRUM pH-titration techni- que $^{3,4}$ as used by IRving and Rossottr ${ }^{5}$. The following mixtures (total vol. $20.0 \mathrm{ml}$ ) were titrated against $0.1 \mathrm{~N} \mathrm{NaOH}$ and the titration curves were plotted:

1. $5.0 \mathrm{ml} 0.01 \mathrm{M} \mathrm{HClO}_{4}+2.0 \mathrm{ml} 1.0 \mathrm{M} \mathrm{NaClO} 4+$ $10.0 \mathrm{ml}$ dioxan $+3.0 \mathrm{ml}$ water; $2.5 .0 \mathrm{ml} 0.01 \mathrm{M} \mathrm{HClO}_{4}$ $+2.0 \mathrm{ml} 1.0 \mathrm{M} \mathrm{NaClO} \mathrm{Na}_{4}+10.0 \mathrm{ml} 0.01 \mathrm{M} \mathrm{H}_{2} \mathrm{NA}+3.0 \mathrm{ml}$ water; $3.5 .0 \mathrm{ml} 0.01 \mathrm{M} \mathrm{HClO}_{4}+2.0 \mathrm{ml} 1.0 \mathrm{M} \mathrm{NaClO}_{4}$ $+10.0 \mathrm{ml} 0.01 \mathrm{M} \mathrm{H}_{2} \mathrm{NA}+2.0 \mathrm{ml} 0.01 \mathrm{M}$ metal ion solution $+1.0 \mathrm{ml}$ water.

In the mixture, the metal-ligand ratio of $1: 5$ was maintained to fulfil the maximum coordination number of the metal. From the proton-ligand formation curve (Fig. 1) the $\log K_{1}{ }^{\mathrm{H}}$ and $\log K_{2}{ }^{\mathrm{H}}$ of $\mathrm{H}_{2} \mathrm{NA}$ have been found to be 8.00 and 6.50 respectively.

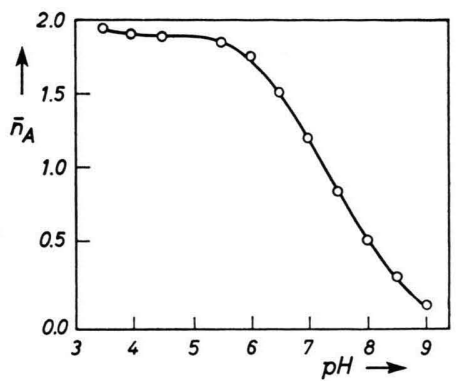

Fig. 1. Formation curve of proton-ligand system of $\mathrm{H}_{2} \mathrm{NA}$.

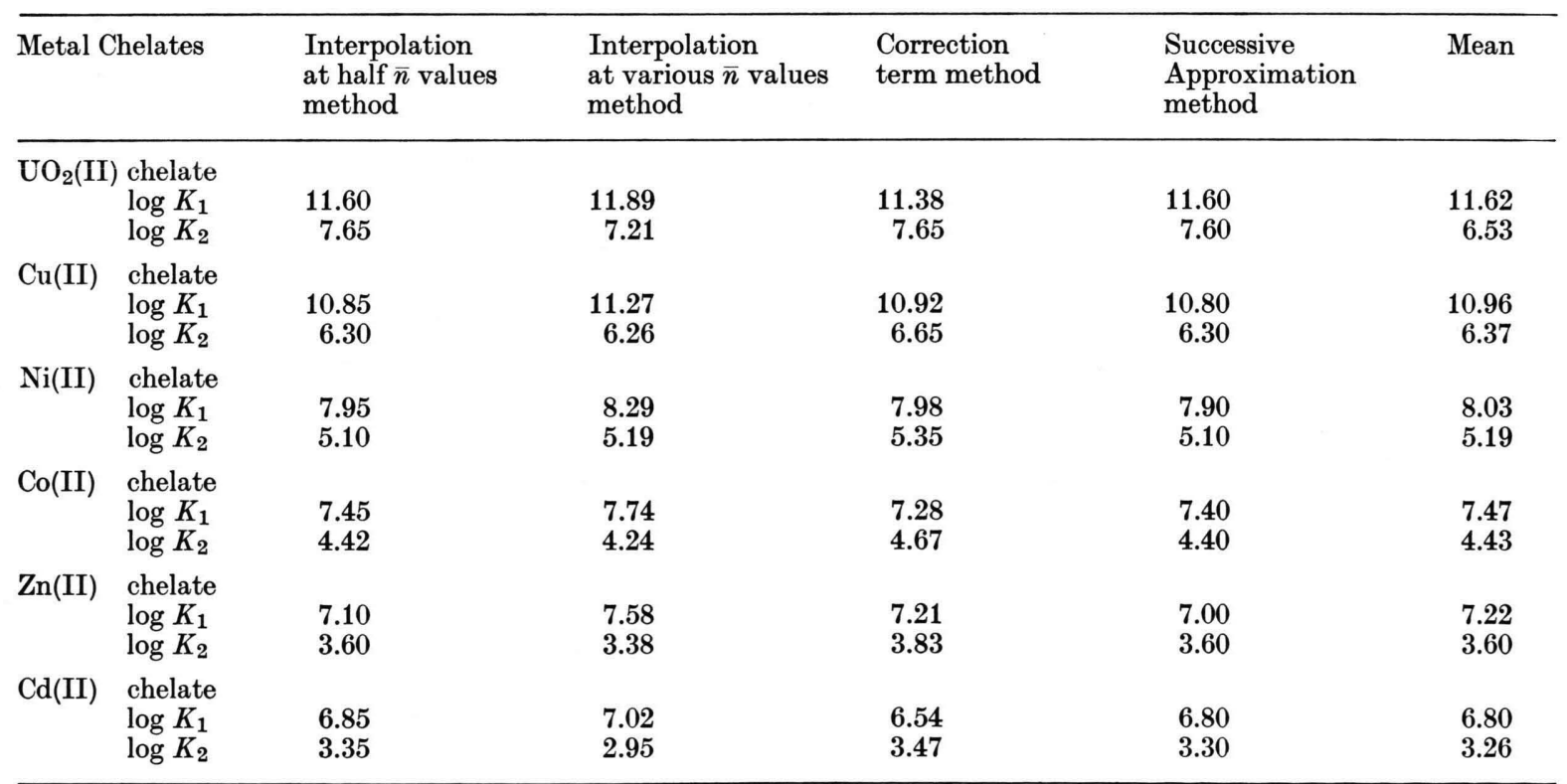

Table I. Formation Constants of some bivalent metal ion chelates of $\mathrm{H}_{2} \mathrm{NA}\left(\mathrm{Temp} .=30 \pm 0.1{ }^{\circ} \mathrm{C}, \mu=0.1 \mathrm{M} \mathrm{NaClO}{ }_{4}\right.$ )

Reprints request to Dr. R. K. Mehta, Department of Chemistry, University of Jodhpur, Jodhpur, India.

1 A. I. Vogel, A Text Book of Quantitative Inorganic Analysis, 3rd Edn., p. 241, Longmans, London 1961.

2 A. I. Vogel, A Text Book of Quantitative Inorganic Analysis, 3rd Edn., p. 233, Longmans, Green \& Co. Ltd., London 1961.
3 J. BJERRUM, Metal ammines formation in aqueous solution, P. Hasse \& Sons, Copenhagen 1941.

4 M. Calvin and K. W. Wilson, J. Amer. chem. Soc. 67, 2003 [1945].

5 H. IRving and H. S. Rossotri, J. chem. Soc. [London] 1954, 2904. 


\section{Results and Discussion}

The method of IRving and RossotTi ${ }^{5}$ was used for deducing the values of $\bar{n}$ and $p L$ from the above data. The $\bar{n}$ values exceeding one indicate the formation of two different complex species. Approximate values of stability constants were read directly from their formation curves (Fig. 2) using BJERRUM half $\bar{n}$ values method. Different methods ${ }^{6}$ have been used to compute the formation constants and the corrected values are given in Table I.

It is evident from the data presented in Table I, that the sequence of formation constants of the bivalent metal ion chelates is, $\mathrm{UO}_{2}>\mathrm{Cu}>\mathrm{Ni}>$ Co $>\mathrm{Zn}>\mathrm{Cd}$, in which that of the first transitional metal ion chelate is in agreement with IRVING and WiLliams rule ${ }^{7}$.

${ }^{6}$ H. Irving and H. S. Rossotti, J. chem. Soc. [London] 1953, 3397.

7 H. IRVing and R. J. P. Williams, J. chem. Soc. [London] 1953, 3192.

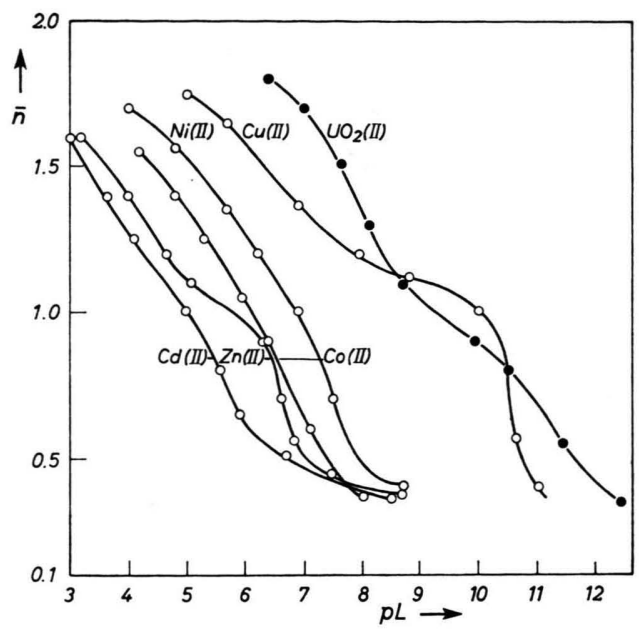

Fig. 2. Formation curves of bivalent metal complexes with $\mathrm{H}_{2} \mathrm{NA}$.

The authors are thankful to University Grants Commission, New Delhi (India) for the award of research fellowship to one of them (V.C.S.). 